\title{
GEOMOPHOLOGICAL CHARACTERISTICS AND ENVIRONMENTAL SENSITIVITY INDEX FOR OIL SPILLS OF ANAVYSSOS BAY, ATTICA
}

\author{
Kourliaftis G. ${ }^{1}$, Kapsimalis V. ${ }^{2}$, Vandarakis D. ${ }^{1,2}$ and Pavlopoulos K. ${ }^{1,3}$ \\ ${ }^{1}$ Harokopio University of Athens, Department of Geography, 70 El. Venizelou St., 17671, \\ Kallithea-Athens, Greece,kourliaf@gmail.com,dbandarakis@hua.gr,kpavlop@hua.gr \\ ${ }^{2}$ Hellenic Centre for Marine Research, Institute of Oceanography, $46.7^{\text {th }} \mathrm{km}$ Athens-Sounion Ave, \\ 19013 Anavyssos, Attica, Greece, kapsim@hcmr.gr \\ ${ }^{3}$ Paris-Sorbonne University Abu Dhabi, Department of Geography and Planning, P.O. Box 38044 \\ AD UAE, Kosmas.Pavlopoulos@psuad.ac.ae
}

\begin{abstract}
The study of the coastal and shallow marine geomorphology of the adjacent bays of Anavyssos and Aghios Nikolaos (southeastern Attica) was carried out by acoustic scanning of the seafloor with an echo sounder and sonar side scan; topographical sections perpendicular to the shoreline, collection and analysis of surface sediments; determination of long-term shoreline displacements by comparing old and modern aerial photographs and satellite imagery. The terrestrial part of the coastal area consists of many landforms, such as lagoons, cliffs, beachrocks, tombola etc. The beaches affected by intense human activity have gentle slopes, low elevations and a coarse-grained texture. The remote sensing analysis showed that, over the last six decades, there are some small shoreline changes of the order of \pm 2 meters. The bays have relatively gentle gradients covered by sand in their shallower parts and patches of Posidonia Oceanica towards the open sea. Taken into account the texture of sediments and landforms that make up the terrestrial part of the coasts, four categories (1st, 2nd, 3rd and 5th) of Environmental Sensitivity Index for oil spill (ESI) have been identified and an ESI map is created serving as a quick reference for oil spill responders and coastal zone managers.

Keywords: Coastal topography, bathymetry, sediments, management.
\end{abstract}

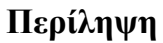

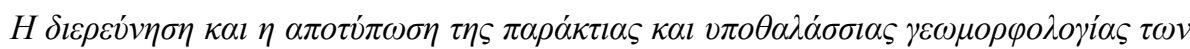

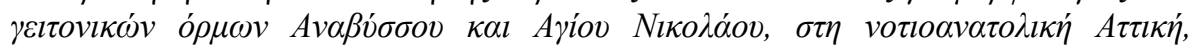

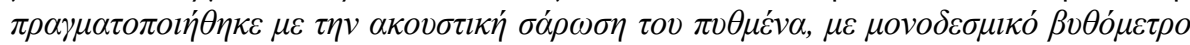

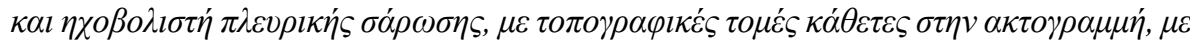

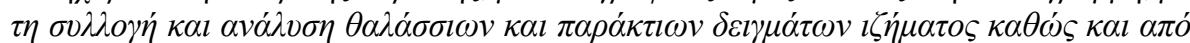

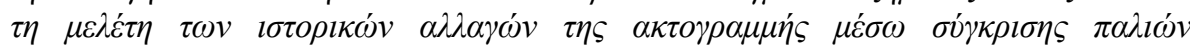

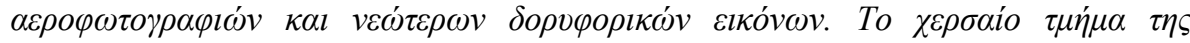

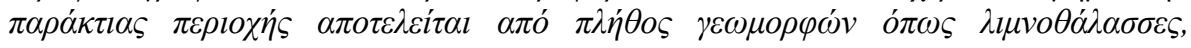

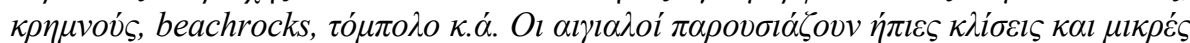

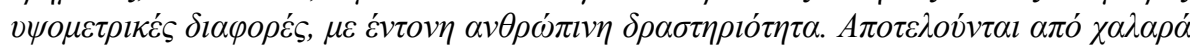

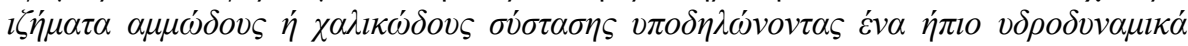




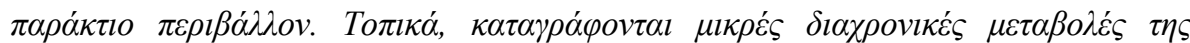

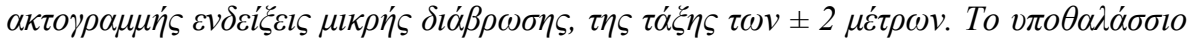

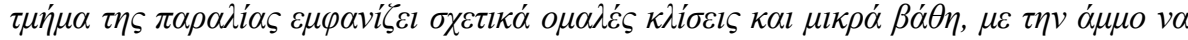

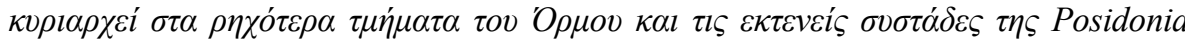

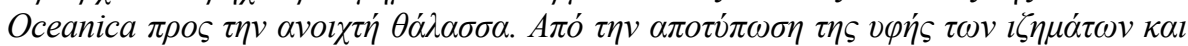

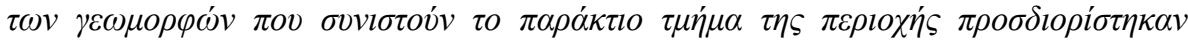

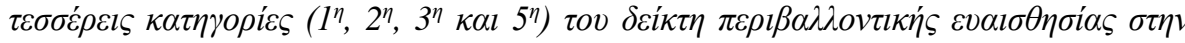

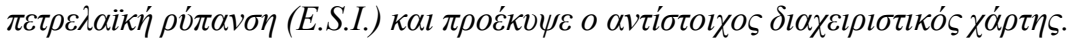

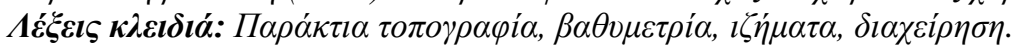

\section{Introduction}

The coastal zone is an area of high environmental, cultural, social and financial value. In recent decades, the configuration of the coast is not only due to the interaction of terrestrial and marine processes (e.g., sediment supply, ripples, currents, etc.), but also to human activities and interventions (Bird, 2008).

The unregulated development of the coastal area (residential, tourist, industrial, maritime, etc.) modifies the long-standing morphodynamic regime of the coast enforcing the processes of erosion or deposition (Woodroff, 2002), as well as it degrades the local environment by discharging organic and inorganic contaminants on the land and/or at sea.

The purposes of the present study are: the mapping of the substrate types of the Anavyssos (Palaia Fokaia) coastal zone and bay, SW Attica (Figure 1); the designation of long-term shoreline displacements during the last seven decades and, consequently, the determination of areas undergoing erosion or deposition; the mapping of the Environmental Sensitivity Index (ESI) for oil spills used in planning to create cleanup strategies before an accident occurs, and to reduce the harmful consequences of oil spills and cleanup.

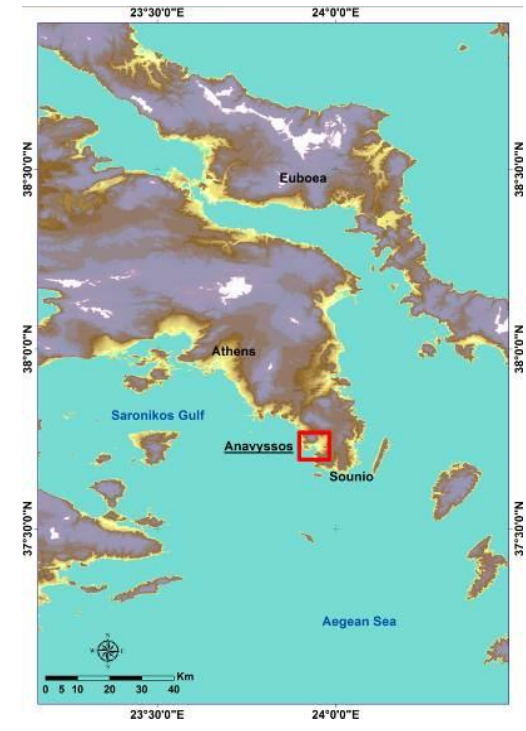

(a)

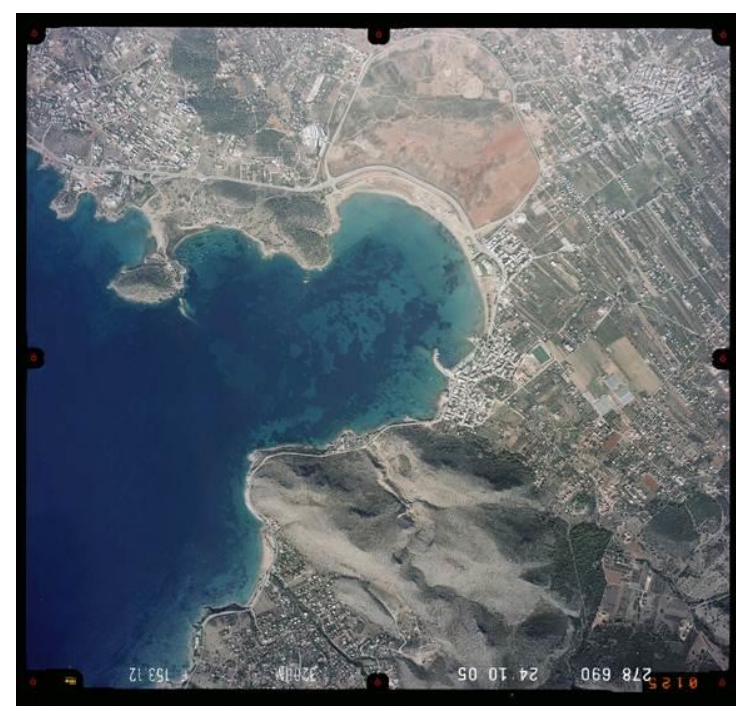

(b)

Figure 1 - (a) Location map and (b) coloured aerial photograph of the Anavyssos and Aghios Nikolaos bays taken in 2005 by the Hellenic Military Geographical Service (HMGS). 


\section{The study area}

The study area is the Anavyssos Bay and the adjacent Aghios Nikolaos inlet, located in southeastern Attica, $50 \mathrm{~km}$ south of Athens and $20 \mathrm{~km}$ north of Sounio (Figure 1). The coastal area of Anavyssos includes an extended lowland with a gradient of $\leq 5 \%$ (Gaki-Papanastasiou, 1985; Markopoulos, 1994). At the seaward end of this plain, there was a natural lagoon, which was operated as saltmarsh till the end of 1970s (Dalakoglou, 1996). The onshore section presents complex tectonic structure, while Quaternary formations are dominant (Pavlopoulos, 1992). The coasts are formed by waves resulting from the wind of south-eastern, southern, southwestern, and western direction. In addition, the large beaches of the area have been fully landscaped by humans for their summer tourist exploitation (Verikiou-Papaspiridakou et al., 2004; Ladakis, 2006).

\section{Materials and Methods}

The bathymetry and seabed morphological features of the bay were conducted by the f/b "Triton I" (HCMR) in May 2015, using a single beam eco sounder (Humminbird 998c HD SI Combo) (Figure 2 ). The bathymetric and side imaging data were collected with the functional emission frequencies of $200 \mathrm{kHz}$ and $450 \mathrm{kHz}$, respectively. The chosen coordinate system was the WGS84, while the projection system implemented was the UTM zone 34N. Beach survey was carried out in July 2015, and 7 descriptive shore-normal profiles, which extended from the sand dunes to the depth of $\sim 2 \mathrm{~m}$, were realized.

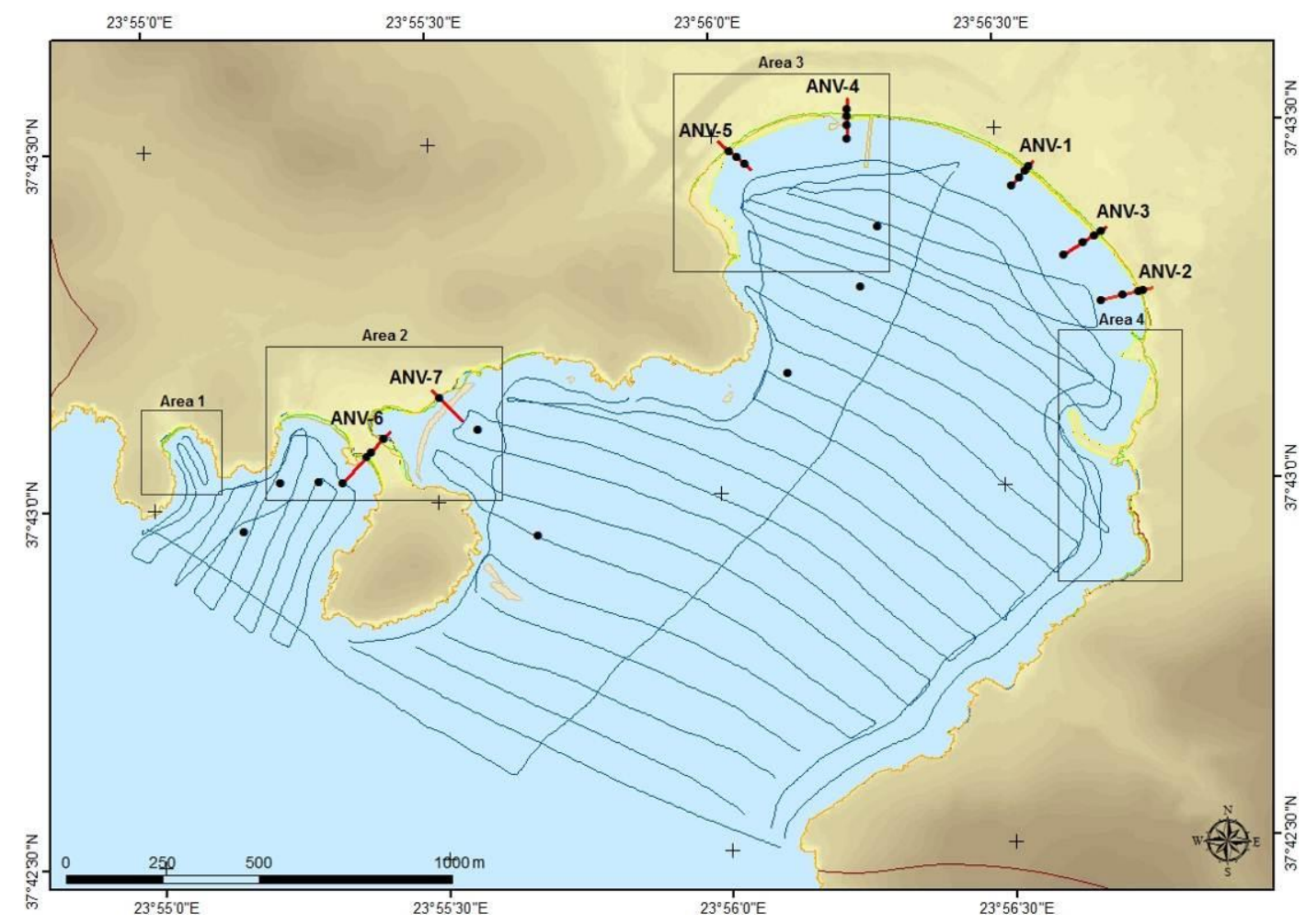

Figure 2 - Position of 7 topographic cross sections carried out along the shoreline (red lines); sampling sites of surface sediments (black dots); and tracks of the single-beam echo sounder and side imaging sonar in the Avavyssos Bay (blue lines).

Granulometric analysis was performed in 32 sediment samples obtained from the beaches (24 samples) and the bottom of bay (8 samples), while the extracted data were statistically processed on the basis of Folk and Ward (1957) method by the use of the GRATISTAT (v.8) software. 
Shoreline spatial changes were identified with the comparison of three aerial photographs (of the years 1960, 1966 and 2008) and three satellite image (of the years 2006, 2011 and 2014). All aerial photographs and satellite images were geometrically corrected and digitized. A maximum total error of $\pm 2 \mathrm{~m}$ was estimated.

The Environmental Sensitivity Index (ESI), firstly applied in 1976, is an integral component of oilspill contingency planning and response and coastal resource management in many countries worldwide Jensen et al. (1998). The ESI is a spatial information system, which is composed of three main components: shoreline ranking system which ranks shoreline types on a scale of 1 to 10; oilsensitive biological resources; and human-use resources of commercial, recreational, or subsistence value (NOAA, 2002).

\section{Results}

\subsection{Historical shoreline displacements}

On the eastern edge of the study area (Area 1), there is a total retreat of the shoreline by $\sim 3 \mathrm{~m}$, in the past 55 years. The shoreline imprinted in 2011 (Figure 3a, blue line) shows a further regression of 2-3 m, which is, however, due to high climbing waves resulting from relatively harsh weather conditions.

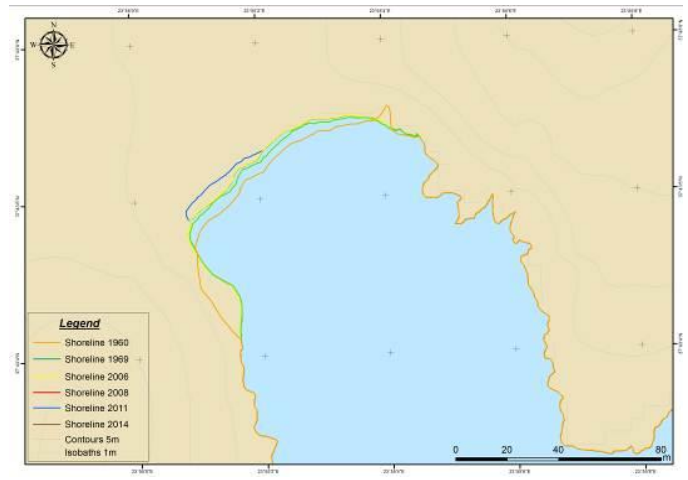

(a)

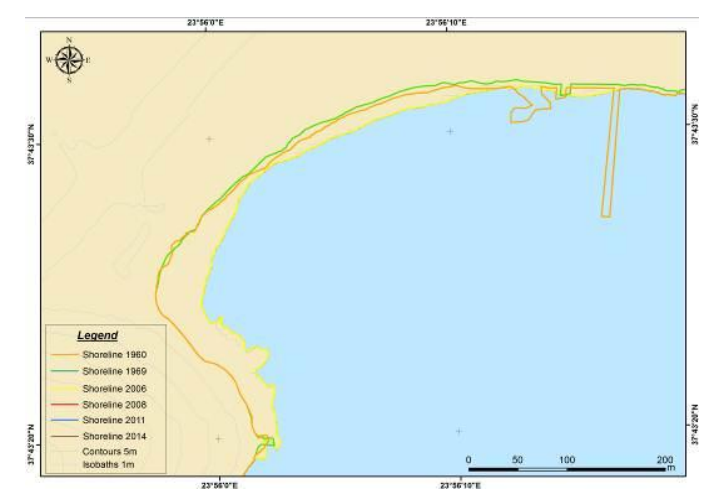

(c)

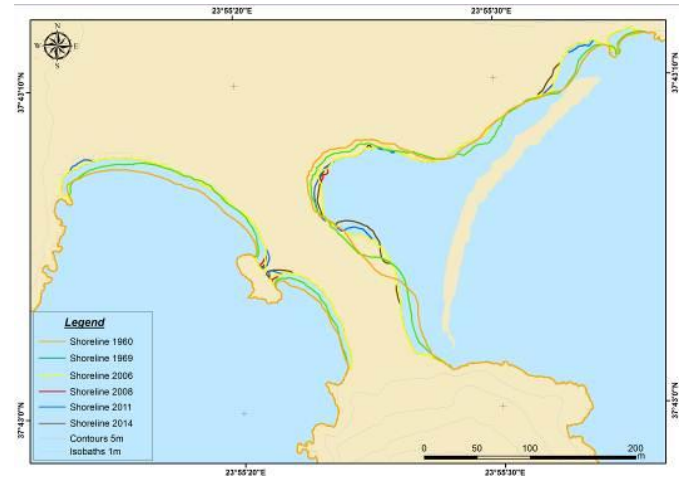

(b)

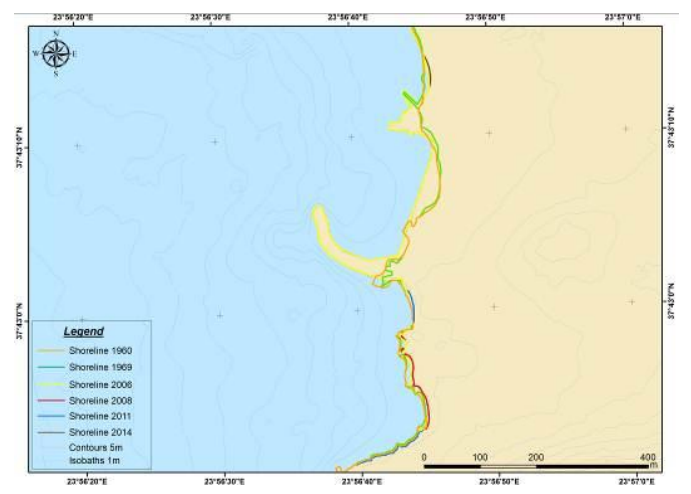

(d)

Figure 3 - Historical shoreline displacements in the Areas: (a) 1; (b) 2; (c) 3; and (d) 4. The locations of each Area are showed in Figure 2. 
In Area 2 (tombolo), erosion (around $3 \mathrm{~m}$ ) dominates across the west coast and the east side at the positions, where the lagoon meets the open sea (Figure 3b). On the contrary, the shoreline situated in front of the lagoon seems to be gaining ground progressively in recent years.

In the western part of the Anavyssos shore (Area 3, Figure 3c) there is a pier that was used to load the salt from the salt marshes. This structure was abandoned and destroyed with the closing of the operation of the saltmarsh, after the end of the 1960s - early 1970s. Furthermore, there seems to be a $35 \mathrm{~m}$ progradation of the coast, resulting from an artificial embankment presumably for the construction of the coastal highway after the closing of the saltmarsh.

Finally, in the eastern part of the Anavyssos Bay (Area 4) the construction of the Palaia Fokaia port stands out, while in its north and south shores there is a slight erosion in the range of $\sim 1 \mathrm{~m}$ (Figure $3 \mathrm{~d}$ ).

\subsection{Coastal Geomophology}

The total length of the shoreline of the study area is $11 \mathrm{~km}$. Almost all along it, there are beaches, the largest of which are the Anavyssos and Aghios Nikolaos (1500 and 400 meters, respectively). In addition, there are some small coasts that are the result of retreating erosion in front of small coastal cavernous recesses at the sea level. The beaches consist mainly of sand and gravel, and in places of pebbles and breccia. In the area there are also coastal cliffs, dunes, tombola, beachrocks and lagoons (Anavyssos and Aghios Nikolaos) (Figure 4).
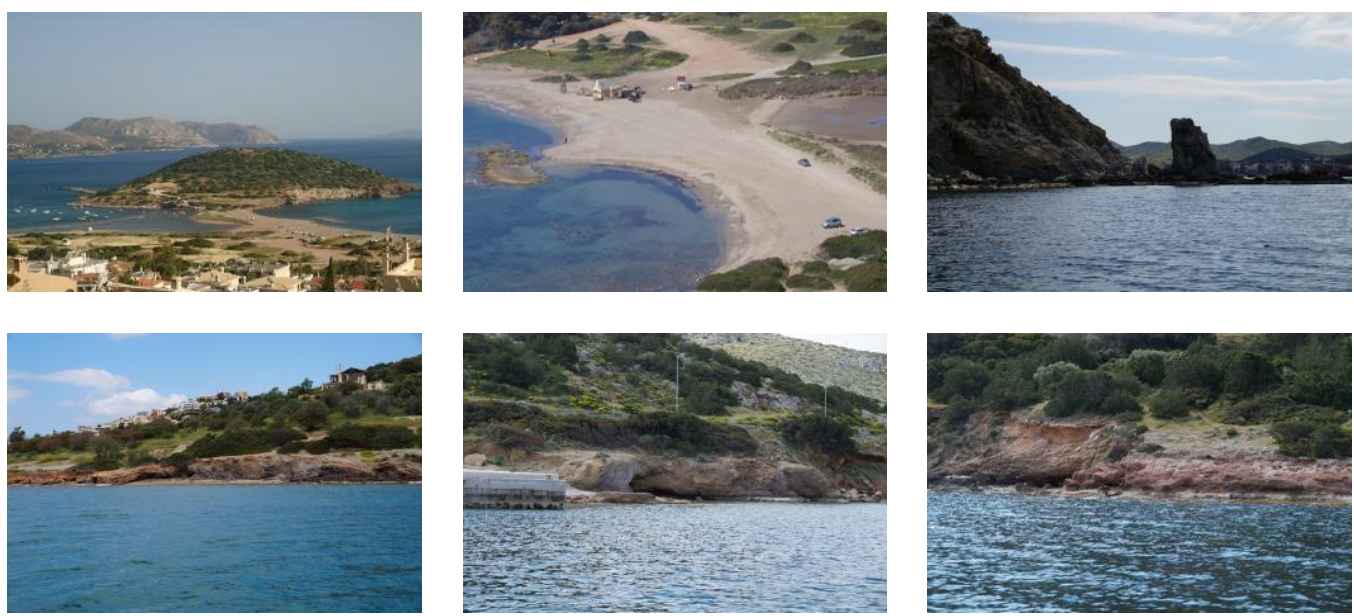

Figure 4 - Photographs showing various coastal landforms in the Anavyssos and Aghios Nikolaos, such as tombolo, beachrocks, stack, caves and cliffs.

Seven (7) topographic cross sections carried out along the shoreline of the study area, combined with the grain analysis of beach sediments (Figure 5). The terrain is low with gentle gradient, surface sediments are mainly sands with sporadic presence of gravel and pebbles, while human interference is present throughout the beaches. The backshore consists of consistent substrate (mainly of sandy composition) used as a parking lot. In the foreshore and offshore section of Anavyssos coast there is a number of longshore bars, at a distance of 20-40 m seaward of the shoreline, at a depth of 0.5-1 m. In the western part of Anavyssos beach (Section ANV-5) the ramp is absent, while in the center of the beach (Section ANV-4) there are numerous tile fragments and boulders, which are possibly from the damaged pier that stood in this position for the saltmarsh operation.

\subsection{Submarine Geomorphology}

The Anavyssos Bay present relatively shallow depths (maximum recorded depth $21 \mathrm{~m}$ ), gentle slopes and non cohesive materials (mainly sand) (Figure 6a). In front of the steep shores of the bay, the depth is relatively low, probably due to the accumulation of landslide materials. The artificial 
submerged breakwater plays a key role in the dynamics of sedimentology of the area preventing the seaward transport of the sand from nearshore.
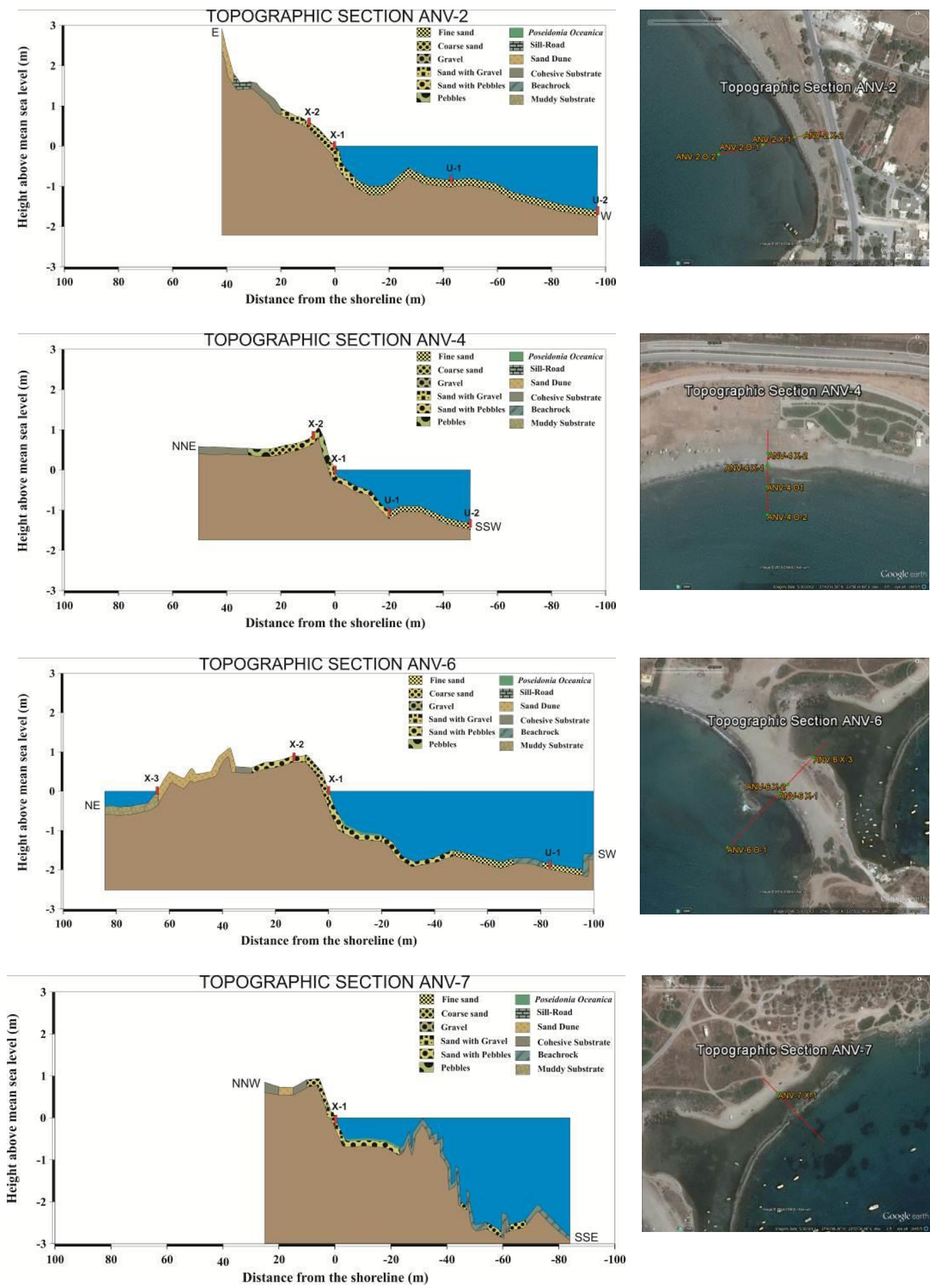

Figure 5 - Topographic sections of the Anavyssos and Aghios Nikolaos coasts. The locations of each section are showed in Figure 2. 
The sand is mostly concentrated on the seafloor sites located in front of the beaches and tombolo sides. The presence of Posidonia Oceanica is detected at depths of more than $3 \mathrm{~m}$ covering the larger part of the seabed (Figure 6b). At depths of 3-17 m, some sandy patches are located, while in deeper waters a well-developed Posidonia Oceanica meadow is present.

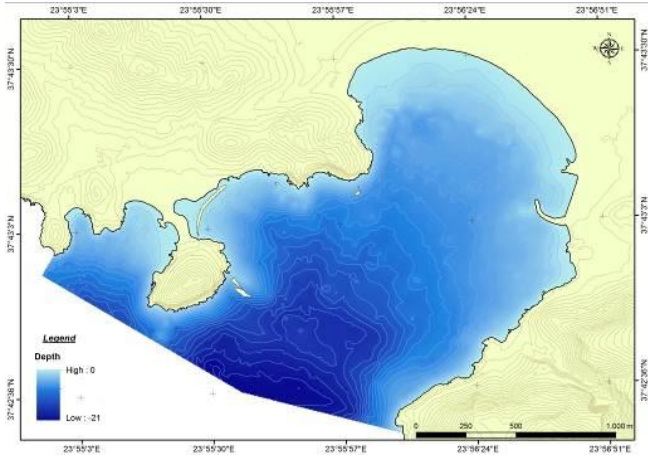

(a)

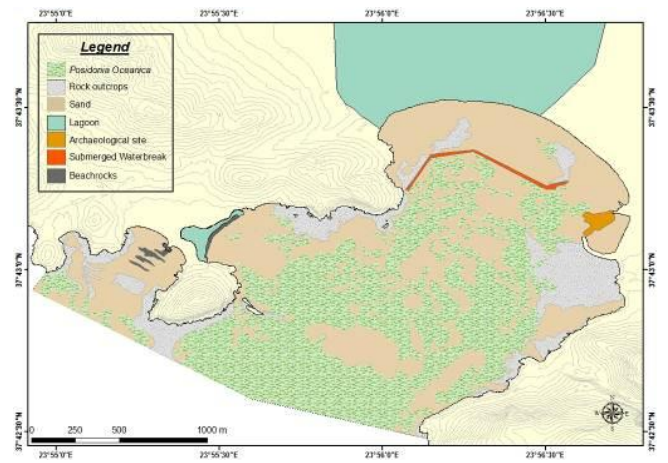

(b)

Figure 6 - (a) Bathymetric map; and (b) Substrate type map of the Anavyssos and Aghios Nikolaos bays.

\subsection{Environmental Sensitivity Index for oil spills}

Based on the index of sensitivity to oil pollution (ESI), four categories of coastal habitats have been identified in the beaches of Anavyssos and Aghios Nikolaos that correspond to rocky shores exposed to wave and vertical impervious manmade structures $(\mathrm{ESI}=1)$, beachrock and rocky platforms (ESI $=2)$, fine-grained and mid-grained sandy beaches $(\mathrm{ESI}=3)$ and mixed sandy and pebbly beaches $(\mathrm{ESI}=5)$.

\section{Discussion}

Small shoreline changes occurred in the last six decades, showing slight retreat in the range of $\sim 2$ $\mathrm{m}$. These changes are a little larger than the statistical error of the method of aerial and satellite imagery analysis $( \pm 2 \mathrm{~m})$, therefore it cannot be concluded with certainty that the specific areas are eroded. In contrast, in the western part of the Anavyssos beach, strong advance of the coastline $(\sim$ $35 \mathrm{~m}$ ) was recorded because of the artificial embankments made in the early 1970s.

The coastal environment of the area is strongly influenced by human activities. There is no longer available solid load at the coastal area because of reduced sediment supply from local rivers, since much of their riverbeds have been filled and built on.

The submarine morphology of the Anavyssos Bay probably owes its characteristics not only to modern morphodynamic factors, but also to processes in land before it was flooded by the sea during the postLast Glacial Maximum period and the subsequent transgression phase of sea level. This assumption is derived by the examination of terrigenous sediments collected from depths of $\sim 10 \mathrm{~m}$.

As regards the environmental sensitivity index for the oil spill, the coastal cliffs and the port infrastructure belong to the $1^{\text {st }}$ category $(\mathrm{ESI}=1)$ and cover $5.45 \mathrm{~km}$ comprising $49 \%$ of the total shoreline. The $2^{\text {nd }}$ category $(\mathrm{ESI}=2)$ includes the shallow rocky coasts with slope $\leq 30^{\circ}$, the beachrocks located in Aghios Nikolaos Bay and the islets situated in the western part of the Anavyssos Bay. It covers $2 \mathrm{~km}$, namely $19 \%$ of the whole littoral zone. The sandy beaches and the sandy banks of the Aghios Nikolaos lagoon belong to $3^{\text {rd }}$ category $(\mathrm{ESI}=3)$, and consist of $27 \%$ of the study area $(2.9 \mathrm{~km})$. Finally, the coastal systems included into the $5^{\text {th }}$ category $(\mathrm{ESI}=5)$ are the sandy-pebbly parts of the central and western beach of Anavyssos and the Aghios Nikolaos lagoon $(5 \%$ or $0.45 \mathrm{~km})$. The last category represents the most 
sensitive coastal habitats of the Anavyssos-Aghios Nikolaos shores, and needs specific managerial action plans in order to face an oil spill pollution risk.

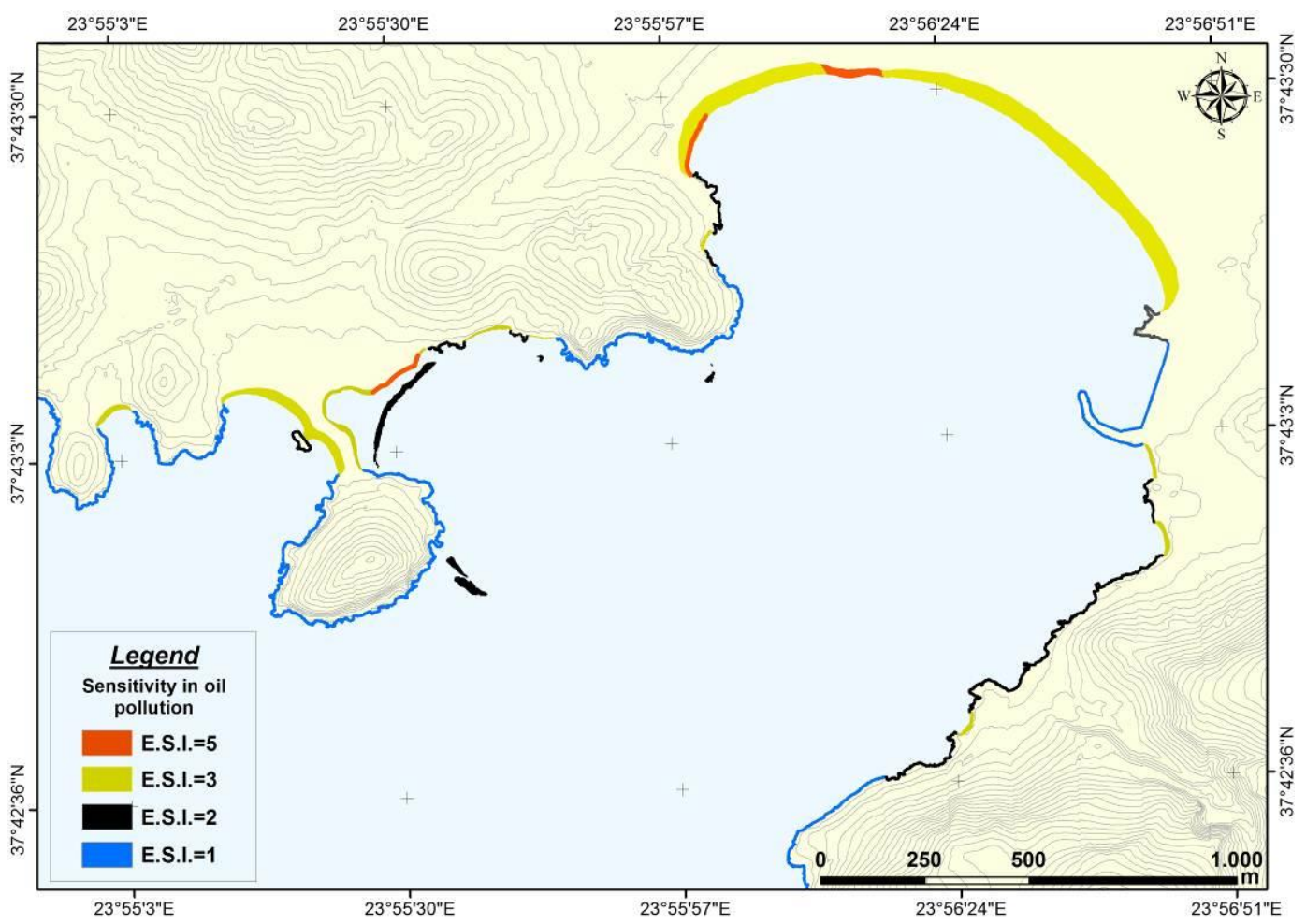

Figure 7 - Environmental Sensitivity Index (ESI) map of the Anavyssos and Aghios Nikolaos coasts.

The recommended actions for their cleaning are: complete purification is not necessary due to the action of the wave and inaccessibility, when ESI = 1; washing with high pressure or sandblasting since they are not particularly ecologically sensitive when ESI $=2$, immediate cleaning and replacement of the sand and attention to the use of heavy machinery in order to avoid entrapment of the oil at greater depths when ESI $=3$; and immediate cleaning is necessary with low-pressure washing and collecting the ingredients separated using the skimmer and sorbents when ESI $=5$.

\section{Conclusions}

The gentle slopes and low elevations of the valley as well as the formation of the lagoon provide data on the deposition rates of the past. The sea shores and the underwater part of the region generally consist of fine material (except for some positions). The coastal and offshore part of the region consists of gentle slopes, loose particles, and small height differences with the recent landforms to be primarily attributable to marine processes of erosion and deposition. The Anavyssos Bay was created because of the land erosion before it submerged by rising sea levels and the low hydrodynamic regime which is unable to alter the characteristics of the underwater plain. In the seacoast region, there is small scale erosion in some places while intense seasonal human activity is present. The bottom cover verifies the low hydrodynamic regime in the bay with the existence of Posidonia (Posidonia Oceanica) from very shallow depths $(3 \mathrm{~m}$.). Finally, the mapping and classification of coastal habitats according to the Environmental Sensitivity Index is necessary information for responsible entities for a faster and more appropriate treatment of a possible oil spill. 


\section{Acknowledgments}

The authors are grateful to Mr V. Mpampas for his valuable help in the fieldtrip work, BSc I. Stavrakaki for the laboratory treatment of the collected sediments, MSc H. Kyriakidou and MSc P. Drakopoulou for the manipulation of the data and G.I.S. analysis.

\section{References}

Bird, E., 2008. Coastal Geomorphology: an Introduction, 2nd Edition John Wiley, Chichester, U. K., $411 \mathrm{pp}$.

Dalakoglou, T., 1996. Anavyssos: The landscape, the people, the life, Lithochrom, Athens, Greece.

Folk, R.L. and Ward, W.C., 1957. Brazos bar: a study of significance of grain size parameters, Journal of Sedimentary Petrology, 27, 3-26.

Gaki-Papanastassiou, K., 1985. Coastal geomorphology of Anavyssos area (Attica) and study of modern marine sediments, MSc Thesis in Oceanography, Department of Geology, National and Kapodistrian University of Athens.

Jensen, J.R., Halls, J.N. and Michel, J., 1998. Systems Approach to Environmental Sensi-tivity lndex (ESI) Mapping for Oil Spill Contingency Planning and Response, Photogrammetric Engineering and Remote Sensing, 64 (10), 1003-1013.

Ladakis, E., 2006. Study of certain modern coastal organosedimentary forms, PhD Thesis, Department of Chemistry, National and Kapodistrian University of Athens.

Markopoulos, K., 1994. Coastal sedimentary formations in the area of Aghios Nikolaos-Anavyssos, Attica, MSc Thesis in Oceanography, Department of Geology, National and Kapodistrian University of Athens.

NOAA, 2002. Enviromental Sensitivity Index Guidelines, Version 3.0., NOAA Technical Memorandum NOS OR\&R 11, Hazardous Materials Response Division, Office of Response and Restoration, NOAA Ocean Service.

Pavlopoulos, K., 1992. Geomorphological evolution of South Attika, Ph.D. thesis, Department of Geology, National and Kapodistrian University of Athens.

Verikiou-Papaspiridakou, E., Skilodimou, H. and Bathrellos, G., 2004. Recording of the changes of the natural geomorphological environment using maps of different issue date. An exam-ple from the coastal zone of the south-western Attica, Bulletin of the Geological Society of Greece, XXXVI, 968-977.

Woodroffe, C.D., 2002. Coasts, Form Process and Evolution, Cambridge University Press, Cambridge, $623 \mathrm{pp}$. 